\title{
Young people's needs and preferences for health resources focused on pornography and sharing of sexually explicit imagery
}

\author{
Cassandra JC Wrighta,b,d, Angela Davis ${ }^{a, b}$, Alyce M Vellaa, \\ Ruby McGrath-Lestera and Megan SC Lima,b,c \\ a Burnet Institute, Melbourne, VIC, Australia \\ b School of Public Health and Preventive Medicine, Monash University, Melbourne, VIC, Australia \\ c Melbourne School of Population and Global Health, University of Melbourne, VIC, Australia \\ ${ }^{d}$ Corresponding author: cassandra.wright@burnet.edu.au
}

\section{Article history}

Publication date: March 2021

Citation: Wright CJC, Davis A, Vella AM,

McGrath-Lester R, Lim MSC. Young people's needs and preferences for health resources focused on pornography and sharing of sexually explicit imagery. Public Health Res Pract. 2020;31(1):e29341912.

First published: 24 October 2019. https://doi. org/10.17061/phrp29341912

\section{Introduction}

Public concerns have been raised about the effects that young people's rapidly increasing access to online pornography has on their mental wellbeing, sexual development and gender norms and expectations. ${ }^{1}$ Young people are also increasingly exchanging personal sexually explicit images (also knowns as 'sexts' or 'nudes'). ${ }^{2}$ When images are shared without the consent of the person in the image, severe social and mental health consequences can arise for the victim. ${ }^{3}$ In acknowledgement of these emerging issues, some recent sexual education campaigns and resources have attempted to provide educational information on pornography use and the sharing of personal sexually explicit images. However, these resources have been criticised as potentially damaging due to their victim-blaming and abstinence-focused approaches. ${ }^{3}$ It is essential to incorporate young people's voices in the development of resources to ensure that they meet the information needs of their audience and improve marketability and appropriateness. There is currently little literature available to guide health promoters in developing resources on this emerging and sensitive topic; we aimed to contribute to addressing this gap in literature in our report.

This report describes insights from young people about information needs and preferences for a future resource focused on young people's pornography use and exchange of personal sexually explicit images.

\section{Methods}

We recruited 16 young Australians (seven males and nine females) aged 15-29 years, via social media advertising. We aimed to recruit a variety of participants with differing genders, education levels and experiences with technology. Participants were asked to complete a 60-minute, online, semistructured interview on a synchronous (real-time) chat-based platform called HipChat (i.e. the interview was an online conversation). This method has shown to be an acceptable and convenient method of eliciting meaningful 
data on sensitive topics from young people. ${ }^{4}$ Participants were reimbursed with a $\$ 20$ voucher. Two researchers (RML and CW) conducted a thematic analysis of deidentified transcripts following steps described by Braun and Clarke. ${ }^{5} \mathrm{RML}$ and $\mathrm{CW}$ jointly developed the coding framework. RML completed the first round of coding, followed by re-coding by $\mathrm{CW}$. CW and $\mathrm{AD}$ were involved in development of themes.

The Monash University Human Research Ethics Committee approved the research (CF15/7 - 2015000006).

\section{Results}

\section{Information needs}

Both male and female participants described the practice of taking and sharing personal sexually explicit images as common among young people but perceived their peers to be uninformed about the risks of nonconsensual distribution (see supplementary material for direct quotes from participants, available from: latrobe.figshare.com/ articles/Supplementary_1_Quotes/10011143). Males particularly felt that young people were largely unaware of the legal ramifications of being the distributor of such images. Females were more likely to discuss requiring information about support services for victims of nonconsensual distribution.

Participants identified a need for information regarding pornography use that increases media literacy (the ability to analyse and evaluate media to understand its influence) and challenges the unrealistic expectations that pornography can give young people. Some participants noted the absence of the discussion of pornography within sexual education and highlighted the importance of open dialogue, given both the prevalence of consumption and its associated stigma. Stigma and shame were frequently mentioned by male participants when discussing their experiences of pornographyrelated education resources.

\section{Framing and format of the resource}

Participants recommended a "sex-positive" approach, compared with the mostly "condescending" resources available, whereby young people are assisted in making informed choices and provided with support, without behaviours being discouraged or shamed. Participants frequently mentioned encountering sexual education resources which were unappealing due to the authoritative and out-of-touch tone of the content. Participants of both genders cited storytelling as a method which may reduce young people's feelings of isolation and stigma related to seeking help while improving the resource's authenticity.

All participants agreed that a website was the best platform for a central resource. Although some thought that social media promotion might improve the reach of a website, the majority insisted that they would be unlikely to engage with material related to sex and pornography use on social media, predominantly because they considered social media to be for communicating with friends only. This was consistent across both genders. One participant highlighted that if an organisation had an established brand, then social media may be a useful tool, but that it may otherwise not be an effective way to build an audience. Participants recommended health promoters carefully consider the appropriateness of different social media channels due to the differing ways that they were used by participants, and their differing appeal to particular age groups (i.e. noting the dying appeal of Facebook among younger age groups). Participants of both genders also noted the importance of both the quality of content and frequency of posts.

\section{Discussion}

Participants in this study identified a range of information needs relating to pornography use and the exchanging of personal sexually explicit images, which they felt were not addressed adequately in existing health resources or education programs. Information about nonconsensual distribution of sexual images is currently available on websites of services providing legal aid, however participants had clearly not been exposed to it. The young people in our study described experiences of encountering one-dimensional resources focused on risk reduction and advocated for more holistic discussions. Previous studies have identified that young people prefer nonjudgmental and even sex-positive approaches when receiving health information and interventions ${ }^{6}$; however, our participants still felt that these preferences were not reflected in campaigns and education programs they had encountered. User-generated content emerged as a practical means of overcoming issues of language, pitch, relevance and tone.

An interesting finding was the mostly negative reaction towards using social media to disseminate health resources and the preference for the resource to be hosted on a website. This implies that young people would rather see sensitive health-related information when they are actively looking for it, rather than have it intrude into a social space where they might encounter it unintentionally (i.e. on a social media feed). Social media is increasingly used for health promotion, and is often touted as a simple, convenient method of directly reaching young people. ${ }^{7}$ However, the young people in our study insisted that social media channels were not an appropriate or effective platform for engaging young people on sensitive health topics. Studies that support this finding refer to the risk posed to young people in terms of 'reputation management' if they are seen to be publicly engaging with material on stigmatised topics. ${ }^{8}$ This is especially pertinent for social media channels that publish users' names rather than linking profiles to anonymous identifiers/handles. Our participants' nuanced 
advice to health promoters about social media highlight that young people are increasingly aware of the quality of design, competent with technology and thus highly critical of poor execution. As such, health promoters cannot expect that being visible on social media is enough - an informed and planned social media strategy is required, or they risk damaging the credibility of their initiative.

\section{Conclusion}

Given the fast pace of changing technology and social media channels, we recommend that health promoters seek the advice and engagement of young people when developing resources, especially when addressing sensitive or emerging topics and if literature is unavailable or outdated. Our findings provide some practical advice to health promoters for developing a resource focused on sensitive sexual health matters such as pornography use and exchange of personal sexually explicit images, particularly relating to use of social media.

\section{Acknowledgements}

This study was fully funded by Telematics Trust, a public charitable trust that promotes the appropriate innovative use of technology in public education and training in Victoria.

\section{Peer review and provenance}

Externally peer reviewed, not commissioned.

\section{References}

1. Lim M, Carrotte $E$, Hellard M. The impact of pornography on gender-based violence, sexual health and well-being: what do we know? J Epidemiol Community Health. 2016;70(1):3-5.

2. Klettke B, Hallford DJ, Mellor DJ. Sexting prevalence and correlates: a systematic literature review. Clin Psychol Rev. 2014;34(1):44-53.

3. Albury K, Crawford K, Byron P, Mathews B. Young people and sexting in Australia: ethics, representation and the law. Sydney: University of New South Wales; 2013 [cited 2019 Oct 9]. Available from: core.ac.uk/download/ pdf/30677128.pdf

4. Barratt MJ. The efficacy of interviewing young drug users through online chat. Drug Alcohol Rev. 2012;31(4):56672.

5. Braun V, Clarke V. Using thematic analysis in psychology. Qual Res Psychol. 2006;3(2):77-101.

6. Davis WM, Shoveller JA, Oliffe JL, Gilbert M. Young people's perspectives on the use of reverse discourse in web-based sexual-health interventions. Cult Health Sex. 2012;14(9):1065-79.

7. Evers CW, Albury K, Byron P, Crawford K. Young people, social media, social network sites and sexual health communication in Australia: "This is funny, you should watch it". International Journal of Communication. 2013;7:18

8. Byron P, Albury K, Evers C. "It would be weird to have that on Facebook": young people's use of social media and the risk of sharing sexual health information. Reprod Health Matters. 2013;21(41):35-44.

\section{Competing interests}

None declared.

\section{Author contributions}

AV was involved in study design, recruitment, data collection and editing of the manuscript. RML was involved in data analysis and contributed to the editing of the manuscript. ML was involved in study design, data analysis, manuscript concept and editing of the manuscript. AD was involved in data analysis, manuscript concept and editing of the manuscript. CW was involved in data analysis, manuscript concept and was primarily responsible for writing the manuscript.

\section{Copyright: (c) (i) (5)(2)}

(c) 2019 Wright et al. This article is licensed under the Creative Commons Attribution-NonCommercial-ShareAlike 4.0 International Licence, which allows others to redistribute, adapt and share this work non-commercially provided they attribute the work and any adapted version of it is distributed under the same Creative Commons licence terms. See: www.creativecommons.org/licenses/by-nc-sa/4.0/ 